\title{
EXPERIENCE-BASED DECISION SUPPORT METHODS USING ORDINAL EXPERT ESTIMATES
}

\author{
Sergey Kadenko \\ National Academy of Sciences of Ukraine \\ The Institute for Information Recording \\ Kyiv, Ukraine \\ E-mail: sergeykadenko@mail.ru
}

\begin{abstract}
Experience-based decision-making support methods using ordinal expert estimates (i.e. alternative rankings) are suggested. The methods can be used when it is impossible or problematic to obtain cardinal estimates and/or criterion weights through direct expert estimation. Cases of one-level and multi-level criteria hierarchies as well as criteria networks are analyzed. The concept of a multi-functional cardinal and ordinal type decision-making support system is proposed.
\end{abstract}

Keywords: ordinal expert estimate, ranking, criterion weight, criteria hierarchy

\section{Introduction}

It is a common knowledge that today expert estimation is widely used in various spheres of human activity. A special place in expert estimation and decision-making support belongs to ordinal estimates, or rankings. Ordinal estimation takes place when it is unnecessary, problematic or impossible to define the exact absolute or relative values of objects' (alternatives') parameters.

In order to avoid further confusion let us first define an ordinal estimate of an alternative or an object as its number in a set of alternatives. Ordinal estimates (or ranks) are assigned to alternatives in the order of increment or decrement of their significance according to a specified criterion. In the general case the number of values of ordinal estimates which can be assigned to the objects from a given set coincides with the number of objects in the set.

The need to define relative criterion weights arises when a decision-maker needs to set up priorities in his/her activity in order to facilitate appropriate distribution of resources and efforts in future. Obviously, most resources should be allocated to criteria, exerting the greatest influence upon the main goal (or global estimation criterion), since they represent the most effective way to achieve this main goal.

In case it is impossible to define weight coefficients directly, through expert estimation, we can calculate them based on the previous experience of cardinal or ordinal alternative estimation. When we are dealing with cardinal estimation experience, we can use various well-known and thoroughly tested approaches, such as least squares method, regression models, neuronal networks and linear programming-based procedures. The question of using ordinal estimates or rankings as a relevant source of information for learning is the main issue we are going to tackle here. If rankings can be used as learning data, then, in case experts are unable to provide an expertise organizer or decision-maker with cardinal estimates, (s)he may at least try to obtain ordinal estimates and use them for criterion weight coefficients calculation. Besides, while building alternative ranking experts are asked simple questions like "Which alternative is better according to the given criterion?" or "Which alternative is the best one in the set? And which alternative is the best among remaining ones?” If an expert is unable to estimate the alternatives directly or build a pair comparison matrix with distinct domination values, such as the one used in the AHP (Saaty 1996, 2008), (s)he may still be able to answer the specified questions and, thus, provide the expertise organizer (or the decision-maker) with alternative rankings, which also carry information.

Several methods are used to obtain alternatives' ranking according to a global criterion, although, as it was shown by many world-known scientists, from (Condorcet, 1785) to (Arrow, 1963), none of these methods is immune to paradoxes and drawbacks. Beside that, in the general case results of using different 
methods are also different. For instance, global (or group) rankings obtained from single-criterion (individual) ones using Condorcet and Borda (weighted summing) methods will almost always differ from each other. But still the problem of aggregating individual (single-criterion) ordinal estimates is being posed and researched by scientists in Ukraine, Russia and western countries due to its immense actuality (Totsenko, 2005).The problem statement is similar to any multi-criteria or group estimation problem formulation, including AHP.

If the problem is posed one way (defining unknown alternative estimates according to global criterion, using single-criterion alternative estimates and criterion weights) than it is relevant to search for a solution of the inverse problem (unknown criterion weights' calculation based on single-criterion and global alternative estimates), and that is what the author is trying to do.

\section{Problem statement}

What is given (initial data) (see Figure 1):

1) A set of alternatives (objects) $A_{1}, A_{2}, \ldots, A_{m}$

2) A set of preferentially independent criteria of alternative estimation [Keeney Raiffa, 1993], which are compatible with each other $C_{1}, C_{2}, \ldots, C_{n}$

3) Ranking of alternatives according to each criterion $\left\{r_{i j}\right\}, i=1 . . m, j=1 . . n$, where $r_{i j}$ is a rank (an ordinal estimate) of the $i$-th alternative according to the $j$-th criterion

4) Strict global ranking of alternatives (alternatives' ordinal estimates according to a global criterion G) $g_{1}, \ldots, g_{m}$

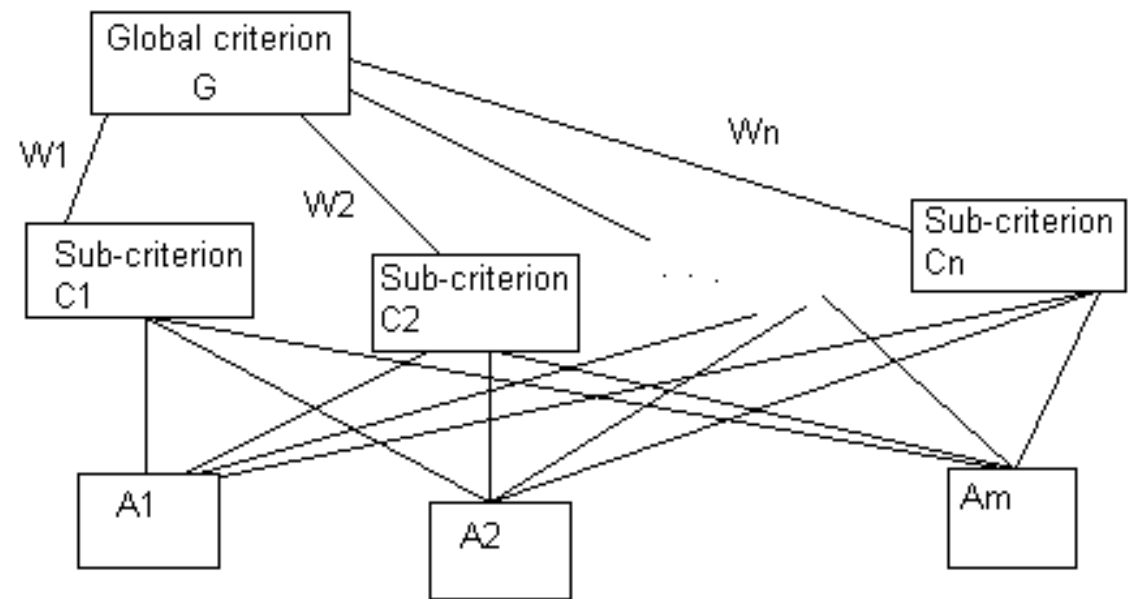

Figure 1. One-level criteria hierarchy

We should find

1) Sufficient existence conditions of a normalized alternative estimation criterion weights' set: $\left\{w_{j}\right\}, j=1 . . n\left\{w_{j}\right\} ; \sum_{j=1}^{n} w_{j}=1, w_{j}>0, j=1 . . n$, preserving the initial global ranking of alternatives after weighted summing of single-criterion ordinal alternative estimates.

2) The extreme points of the weights' acceptability region and its center.

We propose to define the area's center as a simple average of its extreme points' coordinates. This point is easy to find and it represents a more stable solution than any point, lying close to the area's border. Weighted summing (or modified Borda) method of individual rankings' aggregation (Totsenko, 2005) is one of the most commonly used ones. It is not the author's purpose to analyze the pros and cons of its relevance or to compare cardinal or ordinal estimates' aggregation methods. Each expertise (multi-criteria 
estimation precedent) is unique and any method can prove better then other ones. For now we shall only suggest the experience-based weight calculation method using ordinal estimates, i.e., try to solve the problem, inverse to the one posed in Borda method.

\section{Solution algorithm description}

Presumably, the global alternative ranking is a ranking of weighted single-criterion rank sums, so our task is to find a solution for a system of inequalities of the following type:

$$
\begin{aligned}
& \sum_{j=1}^{n} a_{i j} \times w_{j}>0, i=1 . . m-1 \\
& w_{j}>0, j=1 . . n \\
& \text { where } a_{i j}=r_{i+1, j}-r_{i j} .
\end{aligned}
$$

( $i=1 . . m(m-1) / 2$ if we suppose that global ranking transitivity requirement may be unfulfilled).

Each inequality corresponds to a pair comparison of two alternatives $A_{i}$ and $A_{j}$. In general case the system may be redundant and can possibly contain incompatible inequalities. We can turn to iterative weights' calculation algorithm (Kadenko, 2008a), similar to neural network methods (Haykin, 1999), limiting the number of studying epochs from above. The algorithm envisions step-by-step movement of a point on a simplex, in a direction of a normal vector to a given hyper-plain (see Figure 2, illustrating the iterative weights' calculation procedure for 2-dimensional case).

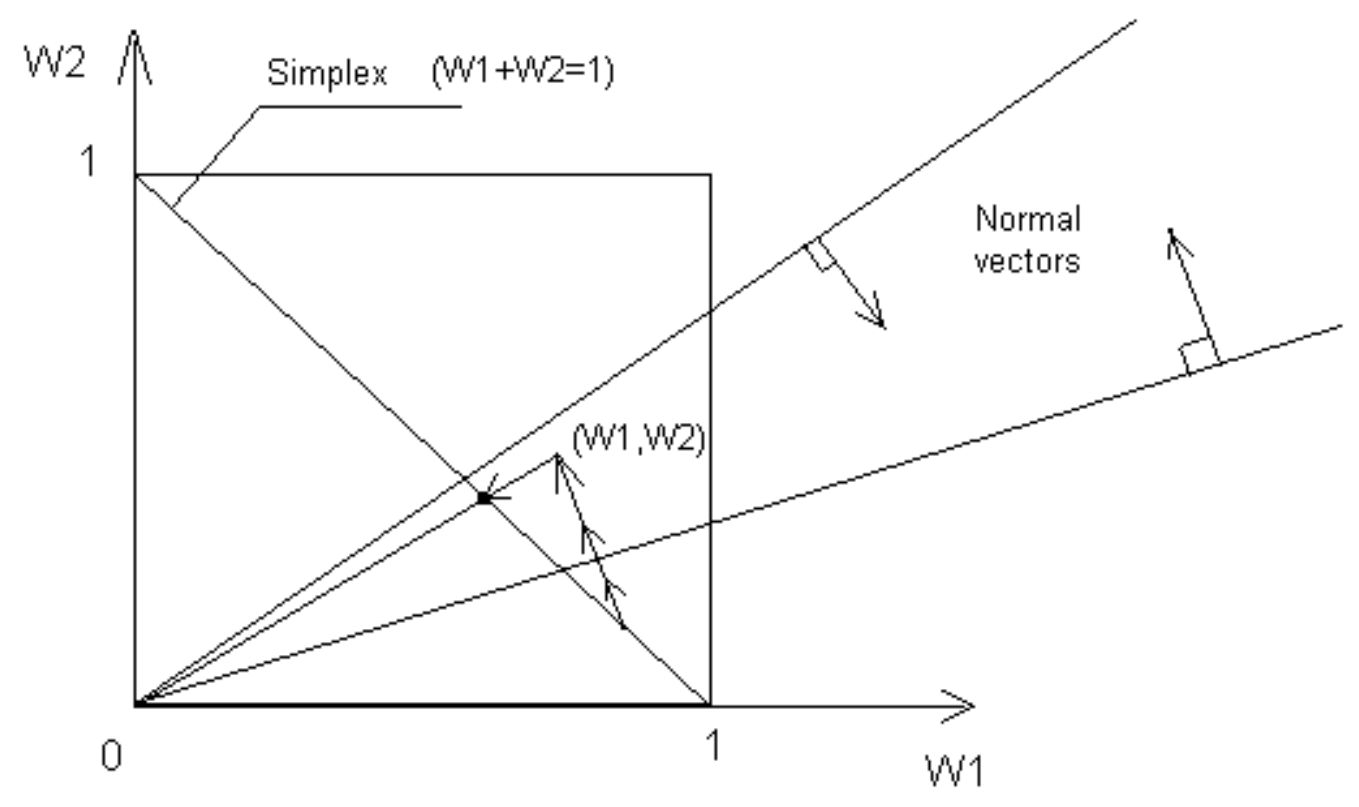

Figure 2

For example, if all the system's inequalities have been processed by the algorithm $k$ times and still the weights do not stabilize, we can stop their iterative fine-tuning and consider the system incompatible. Let us consider a numerical test example. The example was generated as follows. Suppose 5 alternatives were ranked according to 3 criteria. After that a vector of 3 weights was randomly generated. Then a global ranking was built as the ranking of weighted sums of single-criterion ordinal alternative estimates. After that the iterative weight fine-tuning procedure was run. The experiment's results are shown in Table 1. 
Table $1 \mathrm{~A}$ numerical test example for iterative procedure

\begin{tabular}{|c|c|c|c|c|}
\hline Criteria & $C_{1}$ & $C_{2}$ & $C_{3}$ & $\begin{array}{l}\text { Global } \\
\text { criterion } \\
G\end{array}$ \\
\hline Original criterion weights, used for generating global ranking & 0.261 & 0.337 & 0.402 & \\
\hline Alternatives & \multicolumn{4}{|c|}{ Rankings } \\
\hline$A_{1}$ & 1 & 4 & 3 & 3 \\
\hline$A_{2}$ & 5 & 1 & 5 & 4 \\
\hline$A_{3}$ & 4 & 2 & 2 & 2 \\
\hline$A_{4}$ & 2 & 3 & 1 & 1 \\
\hline$A_{5}$ & 3 & 5 & 4 & 5 \\
\hline \multirow[t]{10}{*}{ Inequalities system coefficients } & $\begin{array}{l}4(=1- \\
5)\end{array}$ & $\begin{array}{l}-3(=1- \\
4)\end{array}$ & $\begin{array}{l}2(=5- \\
3)\end{array}$ & \\
\hline & -3 & 2 & 1 & \\
\hline & -1 & 1 & 2 & \\
\hline & 2 & 1 & 1 & \\
\hline & 1 & -1 & 3 & \\
\hline & 3 & -2 & 4 & \\
\hline & -2 & 4 & -1 & \\
\hline & 2 & -1 & 1 & \\
\hline & -1 & 3 & 2 & \\
\hline & 1 & 2 & 3 & \\
\hline $\begin{array}{l}\text { Criterion weights, calculated iteratively with learning speed } \\
\eta=0.001 \text { (iterative fine-tuning starts from equal weight values) }\end{array}$ & 0.277 & 0.347 & 0.377 & \\
\hline
\end{tabular}

Even if the iterative weights' fine-tuning leads us to some point in an $n$-dimensional space, where all the inequalities are fulfilled (i.e., allows to find a weight vector, preserving the global ranking of weighted local alternative rank sums), it does not give us any information about weights' acceptability range.

If we want to make sure that the area, where the system's solutions lie, is (or is not) empty, we should turn to some properties of this area. As we already know, the region of acceptability is limited by a system of linear constraints, or inequalities. Consequently, if the region is not empty, it is convex, and its closure is a compact set (see Figure 3, illustrating a 3-dimensional case). So, the necessary and sufficient condition of the region's existence is the existence of finite number of its extreme points. Any convex combination of the region's extreme points will lie within the region. In our case the region's extreme points are the points, where the simplex $\left(\sum_{j=1}^{n} w_{j}=1, w_{j}>0, j=1 . . n\right.$, $)$ and the hyper-planes given by the inequalities' left sides intersect. Hence, we can find extreme points as solutions of linear equations' systems: each system will consist of $n-1$ hyper-plane equation and the simplex equation $\left(\sum_{j=1}^{n} w_{j}=1, w_{j}>0, j=1 . . n\right.$.). (Each system will contain $n$ equations and $n$ unknown variables (weights)). 


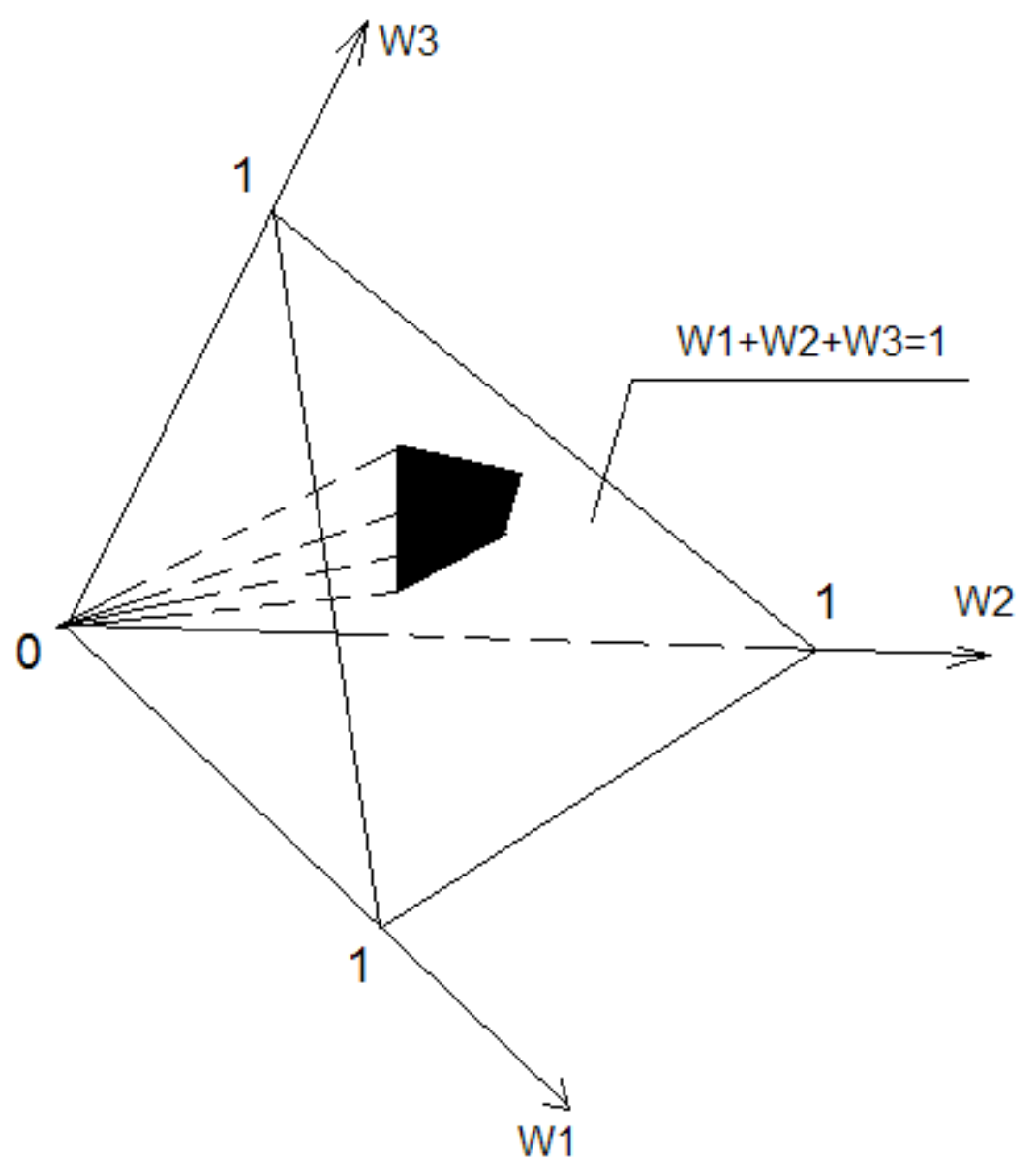

Figure 3

After enumerating all the equation systems we can either define the weights' acceptability range (i.e., its extreme points and "center"), or learn that it is empty.

If the weights acceptability range is empty, we propose to turn to the expert(s), who built the global alternative ranking and ask him herlthem to change it in such a way that the weights' acceptability range is not empty. In order to do this, we must know, what pairs of alternatives should be swapped in the global ranking. The author suggests to look through all the weight vectors, obtained through solving the equation systems, described above, and choose the vectors, on which the minimal Kemeny distance (Kemeny and Snell, 1973) between initial global ranking and weighted local ordinal estimate sums' ranking is reached. Kemeni distance between rankings is 4 times larger than the number of unfulfilled inequalities from system (1) (Kadenko, 2008a), so, since these values are directly related, we are choosing Kemeny distance and not other coefficients (such as Kendall's rank correlation value (Abdi, 2007) or concordation value (Condorcet, 1785)) as an error indicator. Among these vectors we recommend to choose a vector, on which the minimal absolute discrepancy (residual) is reached.

$\sum_{j=1}^{n} a_{i j} \times w_{j}+u_{i}>0, i=1 . . m(m-1) / 2$

$w_{j}>0, j=1 . . n$

$\sum_{i=1}^{m(m-1) / 2} u_{i} \rightarrow \min$

where $u_{i}$ is a non-negative residual value for $i$-th inequality. 
In this case the feedback will demand the smallest changes (i.e. permutations number) in the initial global alternative ranking from the expert, who will be most likely to accept them. Here is another numerical example, this time, illustrating the enumeration of potential acceptability region's extreme points. All the rankings (including the global one) were randomly generated. We suppose that the expert agreed to swap the alternatives in the global ranking.

Table 2

\begin{tabular}{|c|c|c|c|c|}
\hline Criteria & $C_{1}$ & $C_{2}$ & $C_{3}$ & $\begin{array}{l}\text { Global } \\
\text { criterion } \\
\text { G }\end{array}$ \\
\hline Alternatives & \multicolumn{4}{|c|}{ Rankings } \\
\hline$A_{1}$ & 3 & 2 & 2 & 5 \\
\hline$A_{2}$ & 2 & 5 & 1 & 4 \\
\hline$A_{3}$ & 1 & 4 & 4 & 3 \\
\hline$A_{4}$ & 4 & 3 & 3 & 2 \\
\hline$A_{5}$ & 5 & 1 & 5 & 1 \\
\hline \multicolumn{5}{|c|}{$\begin{array}{l}\text { To get a non-empty weights' acceptability region (in order to eliminate contradiction, or transitivity } \\
\text { breach, in the inequalities system), the "expert" should put the alternative } A_{1} \text { between alternatives } A_{4} \text { and } \\
A_{5} \text { : this is the smallest necessary change in the global ranking, according to formulation (2). }\end{array}$} \\
\hline Alternatives & \multicolumn{4}{|c|}{ Alternative rankings after permutations } \\
\hline$A_{2}$ & 2 & 5 & 1 & 5 \\
\hline$A_{3}$ & 1 & 4 & 4 & 4 \\
\hline$A_{4}$ & 4 & 3 & 3 & 3 \\
\hline$A_{1}$ & 3 & 2 & 2 & 2 \\
\hline$A_{5}$ & 5 & 1 & 5 & 1 \\
\hline \multirow{4}{*}{$\begin{array}{l}\text { Extreme points of the weights' acceptability } \\
\text { area }\end{array}$} & 0 & 0.75 & 0.25 & \\
\hline & 0.25 & 0.6875 & 0.0625 & \\
\hline & 0.25 & 0.75 & 0 & \\
\hline & 0 & 1 & 0 & \\
\hline Center of the weights' acceptability region & 0.125 & 0.7969 & 0.0781 & \\
\hline
\end{tabular}

Although in this example after permutations alternative ranking according to the second criterion coincided with their global ranking (which, of course, is not always the case), we can see that the method returns not only the obvious solution $(0,1,0)$, but the whole area where the ranking of weighted singlecriterion alternative ranks is preserved, and its center.

While enumerating potential extreme points of the weights' acceptability range, such requirements as Pareto-optimality of alternatives' set and group order preservation (if $A_{1}$ dominates $A_{2}$ according to all sub-criteria, then it should dominate $A_{2}$ according to global criterion as well) are taken into consideration. Negative weights are also considered unacceptable (see problem statement). This means that all inequalities (constraints), containing only positive and only negative coefficients, are excluded from the enumeration process (skipped) and negative weight values are not analyzed. Still, the extreme points' enumeration procedure is a very time-consuming one. So, it should be noted, that at present development stage the method is targeted at relatively small sets of comparable (not too close and not too far) alternatives, which can be simultaneously analyzed and ranked by an expert according to several criteria.

\section{Comparing the method with other experience-based weight calculation methods}

Due to the loss of information, caused by transition from cardinal to ordinal estimates, it is difficult to find a unified criterion for comparing the described approach with existing experience-based learning methods. Even if the examples (estimation precedents) are generated using specific weight values, the specified method will not return these exact values. It will define the whole acceptability area and the its 
center which will not necessarily coincide with the weight values, set a priori to generate the example. So, the only thing that can be empirically checked is the compatibility or "comparability" of results, obtained through using existing methods and the ordinal estimation-based procedures, specified above.

The method was compared with four experience-based weight calculation methods (group method of data handling, minimal residual method, least squares method and multidimensional linear extrapolation method) on many (hundreds) of examples, generated using specific weight values. First random singlecriterion cardinal "estimates" were generated. Then their weighted sums were built. After that those randomly generated "estimates" were used as a learning sample for four given methods. Then cardinal estimates were substituted with ordinal ones and these were used as a learning sampling for the procedure, described in the previous section.

If the numbers of alternatives $(m=7)$ and criteria $(n=4)$ are relatively small, the four given methods calculate the weights' exact values to the fourth decimal digit.

Some of the results of the aforementioned method's work are shown in Table 3. Here the exact weight values are $0.07,0.13,0.27$ and 0.53 respectively.

\section{Table 3}

\begin{tabular}{|c|c|c|c|c|}
\hline Example number & $\begin{array}{r}1^{\text {st }} \text { criterion } \\
\text { weight }\end{array}$ & $2^{\text {nd }}$ criterion weight & $\begin{array}{r}3^{\mathrm{ra}} \text { criterion } \\
\text { weight }\end{array}$ & $\begin{array}{r}4^{\ln } \text { criterion } \\
\text { weight }\end{array}$ \\
\hline 1 & 0,06 & 0,15 & 0,26 & 0,54 \\
\hline 2 & 0,06 & 0,09 & 0,18 & 0,66 \\
\hline 3 & 0,05 & 0,31 & 0,25 & 0,39 \\
\hline 4 & 0,03 & 0,26 & 0,23 & 0,48 \\
\hline 5 & 0,06 & 0,2 & 0,32 & 0,42 \\
\hline 6 & 0,08 & 0,14 & 0,28 & 0,49 \\
\hline 7 & 0,23 & 0,03 & 0,12 & 0,62 \\
\hline 8 & 0,29 & 0,12 & 0,23 & 0,36 \\
\hline 9 & 0,12 & 0,21 & 0,13 & 0,54 \\
\hline 10 & 0,06 & 0,1 & 0,36 & 0,46 \\
\hline 11 & 0,11 & 0,05 & 0,25 & 0,59 \\
\hline 12 & 0,13 & 0,1 & 0,08 & 0,69 \\
\hline 13 & 0,07 & 0,05 & 0,23 & 0,64 \\
\hline 14 & 0,13 & 0 & 0,23 & 0,65 \\
\hline 15 & 0,11 & 0,25 & 0,19 & 0,46 \\
\hline 16 & 0,06 & 0,26 & 0,07 & 0,61 \\
\hline 17 & 0,01 & 0,17 & 0,27 & 0,54 \\
\hline 18 & 0,19 & 0,31 & 0,12 & 0,39 \\
\hline 19 & 0,05 & 0,25 & 0,23 & 0,47 \\
\hline 20 & 0,02 & 0,33 & 0,07 & 0,58 \\
\hline 21 & 0,08 & 0,3 & 0,23 & 0,38 \\
\hline 22 & 0,07 & 0,14 & 0,25 & 0,53 \\
\hline ge value & 0,09 & 0,17 & 0,21 & 0,52 \\
\hline value & 0,07 & 0,13 & 0,27 & 0,53 \\
\hline
\end{tabular}

As we see, the average weights' values, obtained from 22 estimation precedents, are quite close to the ones, used for building cardinal estimates. If global rankings were built as rankings of weighted alternatives' estimates according to sub-criteria, the results would be even better. So, we can say, that in spite of loss of information witnessed during substituting cardinal estimates with ordinal ones, the average weights (especially, the larger ones, which is quite natural), calculated using the method are not far from initial exact weight values. 


\section{Examples}

\subsection{World University Ranking}

The first example of the method's testing on real data concerns the problem, which has been a subject of many research works, discussions and debates for some time now. We are talking about university ranking. Many world and national educational establishments' ranking systems were developed during the last few years. As for world university rankings, the most famous estimation systems are THES (THES, 2009), SJTU (SJTU, 2006) and Webometrics (Webometrics, 2009). In general, each of the three models envisions weighted summing of the establishments' estimates according to several criteria. These models were criticized a lot and many alternative approaches to university ranking, including statistical and hierarchical ones, were suggested (Steiner, 2005; Guarino, Ridgeway, Chun and Buddin, 2005; Totsenko, Kadenko and Sigal, 2008). Criterion weight coefficients, applied for obtaining global ratings and rankings were defined by the rankings' authors through direct estimation (although in general case they could be calculated based on estimation experience; we are dealing with a one-level hierarchy here and the universities' estimates according to the "peer review" or "recruiter review" criteria could be used as their "global" estimates). These weights will be used for verifying the methods' results in this example. Universities' estimates according to each criterion were normalized by maximal value.

The author used a fragment of the 2008's THES world university ranking as a learning sample for weights' calculation using ordinal and cardinal estimates.

The detailed methodology of THES ranking can be found on the THES web-site (THES, 2009). The initial data for the experiment is as follows (see Table 4; the ranking of the given 10 establishments $(m=10)$ according to $6(n=6)$ criteria is shown in brackets):

Table 4

\begin{tabular}{|l|l|l|l|l|l|l|l|}
\hline $\begin{array}{l}\text { University } \\
\text { name }\end{array}$ & $\begin{array}{l}\text { Peer } \\
\text { review } \\
\text { score }\end{array}$ & $\begin{array}{l}\text { Recruiters' } \\
\text { review } \\
\text { score }\end{array}$ & $\begin{array}{l}\text { Student/staff } \\
\text { ratio }\end{array}$ & $\begin{array}{l}\text { Citations/staff } \\
\text { score }\end{array}$ & $\begin{array}{l}\text { International } \\
\text { staff score }\end{array}$ & $\begin{array}{l}\text { International } \\
\text { student } \\
\text { score }\end{array}$ & $\begin{array}{l}\text { Overall } \\
\text { score }\end{array}$ \\
\hline $\begin{array}{l}\text { University } \\
\text { College, } \\
\text { London }\end{array}$ & $96(2)$ & $99(1)$ & $100(1)$ & $89(3)$ & $96(1)$ & $100(1)$ & $\begin{array}{l}98,1 \\
(1)\end{array}$ \\
\hline $\begin{array}{l}\text { Kyoto } \\
\text { University }\end{array}$ & $99(1)$ & $87(4)$ & $80(3)$ & $91(2)$ & $30(8)$ & $26(10)$ & $\begin{array}{l}87,4 \\
(2)\end{array}$ \\
\hline $\begin{array}{l}\text { Ecole } \\
\text { Normale, } \\
\text { Paris }\end{array}$ & $93(4)$ & $72(5)$ & $68(5)$ & $99(1)$ & $29(9)$ & $69(4)$ & $\begin{array}{l}84,8 \\
(3)\end{array}$ \\
\hline $\begin{array}{l}\text { University } \\
\text { of Illinois }\end{array}$ & $94(3)$ & $67(6)$ & $43(9)$ & $72(5)$ & $37(7)$ & $51(6)$ & $\begin{array}{l}73,2 \\
(4)\end{array}$ \\
\hline $\begin{array}{l}\text { University } \\
\text { of } \\
\text { Jerusalem }\end{array}$ & $89(5)$ & $25(9)$ & $35(10)$ & $89(3)$ & $70(4)$ & $33(8)$ & $\begin{array}{l}69,5 \\
(5)\end{array}$ \\
\hline $\begin{array}{l}\text { University } \\
\text { of Leeds }\end{array}$ & $72(6)$ & $98(2)$ & $57(6)$ & $50(8)$ & $71(3)$ & $64(5)$ & $\begin{array}{l}68,3 \\
(6)\end{array}$ \\
\hline $\begin{array}{l}\text { University } \\
\text { of Pierre } \\
\text { and Marie } \\
\text { Curie, } \\
\text { Paris }\end{array}$ & $66(7)$ & $17(10)$ & $89(2)$ & $40(9)$ & $24(10)$ & $90(3)$ & $61(7)$ \\
\hline $\begin{array}{l}\text { University } \\
\text { of Bath, } \\
\text { UK }\end{array}$ & $\begin{array}{l}49 \\
(10)\end{array}$ & $98(2)$ & $46(8)$ & $55(6)$ & $52(7)$ & $29(9)$ & $\begin{array}{l}60,7 \\
(8)\end{array}$ \\
\hline
\end{tabular}




\begin{tabular}{|l|l|l|l|l|l|l|l|}
\hline $\begin{array}{l}\text { Queen } \\
\text { Mary } \\
\text { University } \\
\text { of London }\end{array}$ & $55(8)$ & $66(7)$ & $77(4)$ & $23(10)$ & $96(1)$ & $92(2)$ & $\begin{array}{l}59,1 \\
(9)\end{array}$ \\
\hline $\begin{array}{l}\text { University } \\
\text { of } \\
\text { Twente, } \\
\text { NL }\end{array}$ & $\begin{array}{l}52 \\
(10)\end{array}$ & $48(8)$ & $57(6)$ & $51(7)$ & $68(5)$ & $50(7)$ & 54,3 \\
\end{tabular}

It should be noted that all the universities were taken from different parts of the ranking (which includes 200 establishments, closely following one another), so that their global ratings could differ substantially (again, alternatives should be comparable). Here (in Table 5) are the exact criterion weights' values and the results of different methods' work:

Table 5

\begin{tabular}{|l|l|l|l|l|l|l|}
\hline & $\begin{array}{l}\text { Peer } \\
\text { review } \\
\text { score }\end{array}$ & $\begin{array}{l}\text { Recruiters' } \\
\text { review } \\
\text { score }\end{array}$ & $\begin{array}{l}\text { Student/staff } \\
\text { ratio }\end{array}$ & $\begin{array}{l}\text { Citations/staff } \\
\text { score }\end{array}$ & $\begin{array}{l}\text { International } \\
\text { staff score }\end{array}$ & $\begin{array}{l}\text { International } \\
\text { student score }\end{array}$ \\
\hline Exact weight & 0,4 & 0,1 & 0,2 & 0,2 & 0,05 & 0,05 \\
\hline $\begin{array}{l}\text { Weight } \\
\text { calculated using } \\
\text { university } \\
\text { rankings }\end{array}$ & 0,32 & 0,12 & 0,16 & 0,33 & 0,02 & 0,06 \\
\hline $\begin{array}{l}\text { Linear } \\
\text { extrapolation } \\
\text { method }\end{array}$ & 0,46 & 0,14 & 0,21 & 0,14 & 0,04 & 0,01 \\
\hline $\begin{array}{l}\text { Minimal } \\
\text { residual method }\end{array}$ & 0,40 & 0,10 & 0,21 & 0,21 & 0,05 & 0,05 \\
\hline $\begin{array}{l}\text { Least squares } \\
\text { method }\end{array}$ & 0,35 & 0,14 & 0,21 & 0,25 & 0,05 & 0,05 \\
\hline $\begin{array}{l}\text { Group method } \\
\text { of data handling }\end{array}$ & 0,35 & 0,14 & 0,21 & 0,24 & 0,05 & 0,05 \\
\hline
\end{tabular}

As we see, in this case the weights, obtained using cardinal estimates are not far from the values, calculated based on ordinal estimation experience. The point is that if criterion weights are calculated based on previous years' estimates, then some forecasts concerning the universities' ratings and/or rankings for the coming year can be made.

Weights' calculation based on establishments' estimation experience was suggested as one of the approaches to be used in the university ranking methodology, set forth in (Totsenko, Kadenko and Sigal, 2008). A more comprehensive report describing the whole methodology was submitted to the National Fundamental Research Foundation of Ukraine, where it won a tender competition.

\subsection{Comparing the candidates applying for a vacancy in an information consulting (or any other) company}

Here is another application, suggested by the manager of one of Kiev information consulting companies. Suppose there are several candidates applying for a job in a company. They should be ranked according to several criteria of unknown weights. Criteria are defined by the company (department) management. Employees who are already working in the company (department) complete questionnaires, providing single-criterion (in general case, ordinal) estimates of their skills. Then a global ranking of working employees is conducted by their manager, who knows them well and is able to assess their general skills level. Using these rankings as sampling data, we can calculate the criterion weights. And after that the 
candidates for the new vacancy can complete the same questionnaires and their ranking can be built using the weight coefficients already obtained.

It should be stressed that if at least one comparison criterion is represented by ordinal alternative estimates, then all other estimates should also be substituted with ranks and weight coefficients should be calculated using the specified method (i.e. ordinal estimates shouldn't be summed with cardinal ones).

Since the ordinal scale range depends on the number of alternatives in the given set, it is obvious, that adding new alternatives to the given ordinal estimation precedent (a set of alternatives ranked according to several criteria and to a global criterion) is irrelevant. In this case rank reversals will surely occur and even the scale itself will shift causing many changes in rank values.

\section{Method's extension to multilevel hierarchies and networks}

The method can also be applied to multilevel hierarchical and network-type structures. In case of a treetype hierarchy alternatives should be ranked according to the tree's "root" (the global criterion) and "leaves" (lowest-level sub-criteria). These ordinal estimates can be used for calculating the leaves' weights (or, their partial impact coefficients (Totsenko, 2002). After that, simple arithmetic operations (solving a few linear equation systems (Kadenko, 2008b)) allow to calculate any intermediate-level criterion weight in the hierarchy (See Figure 4A).
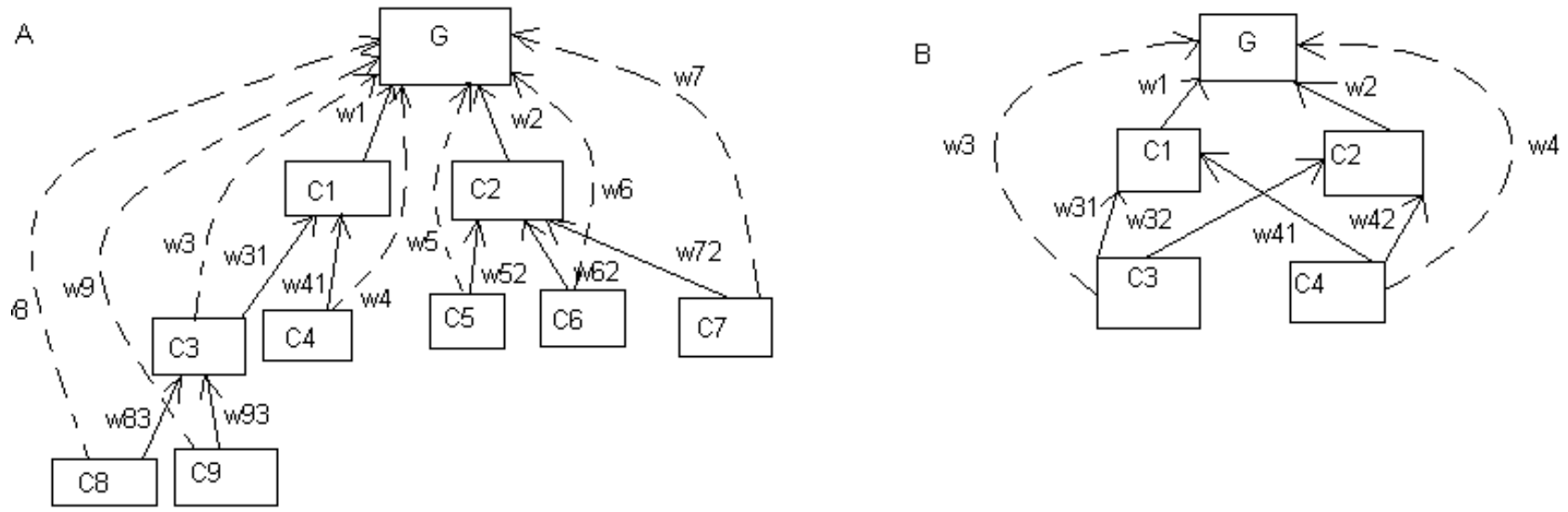

Figure 4

In case of a network-type structure (see Figure 4B) the information, provided by alternatives' ranking according to the main goal (global) criterion and to the lowest-level criteria is insufficient for unambiguous weights' vector calculation. Although the "leaves"' weights can be calculated, the network's structure (in general case) does not let us calculate the intermediate criteria weights, although some values can be obtained using, for example, perceptron-type iterative fine-tuning of the weights (this issue can be a subject of a separate further study).

If alternatives are ranked according to all intermediate-level criteria, then the weights' calculation procedures should be applied to each hierarchy (or network) level separately.

\section{Integrating the approach into larger decision-making support systems}

A long-term task, concerning the implementation of the ordinal estimation experience-based approach, obviously, envisions the creation of a multi-functional automated workplace or even a decision-making support system, incorporating multi-criteria group ordinal and cardinal estimation methods as well as experience-based learning procedures. Presently, the Department of Analytical Methods of Information Technologies of the Institute for Information Recording (Kiev, Ukraine) is developing new versions of "Solon" decision-making support system (Totsenko, 2002), which is successfully applied for various practical as well as experimental purposes. The DSS interface screenshot is shown on Figure 5. In view of 
the aforesaid it would be appropriate to incorporate the specified methods (existing and newly developed ones) into the system in order to make it more universal and multi-functional.

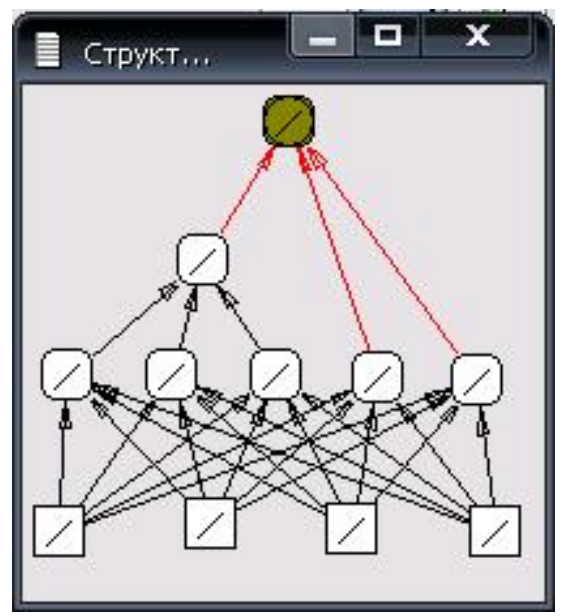

Figure 5

\section{Conclusions}

The key conclusion which can be drawn at the current stage of the research is that, although none of the individual or single-criterion rankings' aggregation procedures is perfect, ordinal estimation experience can and should be used as the data source for weight coefficients' calculation, when it is problematic or impossible to obtain any other estimates beside ordinal ones.

The method described in the paper is targeted at relatively small numbers of comparable alternatives and estimation criteria (echoing the psycho-physiological constraints of human mind), which is often the case with expert estimation precedents. It searches for a stable solution and does not require any additional heuristic guesses to be made. The given method envisions a time- and computer memory-consuming enumeration of the potential extreme points of the weights' acceptability area. But, on the other hand, it gives the decision maker or the expertise organizer thorough information concerning the existence of this area and (in case it is empty) organizing feedback with the expert.

Further research will be targeted at developing other, less laborious learning procedures (not necessarily based on linear programming apparatus), using ordinal estimation experience, and integrating them into existing and new decision-making support systems. Another direction of future research concerns an attempt to extend the methodology to the case of non-strict and fuzzy rankings.

\section{REFERENCES}

Abdi, H. (2007). Kendall rank correlation. In N.J. Salkind (ed.), Encyclopedia of Measurement and Statistics (pp. 508-510). Thousand Oaks (CA): Sage.

Arrow, K. J. (1963). Social Choice and Individual Values, 2nd ed. Wiley, New York.

Marquis de Condorcet (1785). Essai sur l'application de l'analyse á la probabilité des décisions rendues á la pluralité des voix (in French). Retrieved October 3, 2008, from http://gallica.bnf.fr/ark:/12148/bpt6k417181

Haykin, S. (1999), Neural Networks: A Comprehensive Foundation, Prentice Hall. 
Guarino, C., Ridgeway G., Chun, M., \& Buddin, R. (2005). Latent Variable Analysis: A New Approach to University Ranking. Higher Education in Europe 30(2), 147 - 165.

Kadenko, S. V. (2008). Modified Method of Relative Weights’ Determination Based on Ordinal Estimates (in Ukrainian). Data Recording, Storage and Processing, 10(1), 137-149.

Kadenko, S. V. (2008). Determination of Criteria Tree's Parameters Based on Ordinal Estimates (in Russian). Problemy Upravleniya i Informatiki, 4, 84-92.

Keeney, R. L., \& Raiffa, H. (1993). Decisions with Multiple Objectives: Preferences and Value Tradeoffs. Cambridge University Press, New York, 1993.

Kemeny, J. G., \& Snell, L. (1973) Mathematical Models in the Social Sciences. MIT Press, Cambridge, MA.

Saaty, T. L. (1996). The Analytic Network Process: Decision Making with Dependence and Feedback. RWS Publications.

Saaty, T. L. (2008). Relative Measurement and Its Generalization in Decision Making; Why Pairwise Comparisons are Central in Mathematics for the Measurement of Intangible Factors; The Analytic Hierarchy/Network Process. RACSAM 102 (2), 251-318.

Steiner, J. E. (2005). World University Rankings - A Principal Component Analysis. Retrieved December 4, 2006 from http://arxiv.org/ftp/physics/papers/0605/0605252.pdf

Totsenko, V. G. (2002). Methods and Systems of Decision-making Support (in Russian). Naukova dumka, Kiev.

Totsenko, V. G. (2005). Method of Determination of Group Multicriteria Ordinal Estimates with Account of Expert Competence. Journal of Automation and Information Sciences 37(10), 19-23.

Totsenko, V. G., Kadenko, S. V., \& Sigal, T. G. (2008). On One Approach to Rating of Higher Educational Institutions. Journal of Automation and Information Sciences, 40(1), 46-54.

Shanghai Jiao Tong University (SJTU) 2005 Academic Ranking of World Universities (2006). Retrieved December, 4, 2006 from http://ed.sjtu.edu.cn/rank/2005/ARWU2005 Top100.htm

Times Higher Education Supplement (THES) 2008 World University Ranking (2009). Retrieved February, 20, 2009 from http://www.timeshighereducation.co.uk/hybrid.asp?typeCode=243\&pubCode=1\&navcode=137

Webometrics: World Universities' Ranking on the Web (2009). Retrieved February, 20, 2009 from www.webometrics.info 